\title{
Comparison of MRI Findings with Arthroscopy in Knee Injuries
}

\author{
Priya Gaddgi Modi', Anmol Modi ${ }^{2}$ \\ ${ }^{1}$ Assistant Professor, Department of Radiology, Dr B R Ambedkar Medical college, Bengaluru, Karnataka, ${ }^{2}$ Fellow in Body imaging, Columbia Asia hospital, \\ Bengaluru, Karnataka.
}

\section{Abstract}

Background: The knee joint can be imaged using a variety of modalities of which MRI is the most recognized technique posing an excellent imaging modality for all the components of the knee joint namely cartilage, ligaments, tendons, menisci, muscles, bone and bone marrow. Injuries to the intra articular structures can be diagnosed with a high degree of sensitivity and specificity. Subjects and Methods: Patients with history of pain in the knee with or without swelling where MRI was used as a modality in diagnosing the cause. All patients will be subjected to MR imaging and followed by Arthroscopy. Results: Out of the 40 ACLs diagnosed as completely ruptured at MRI, 27 were confirmed to be completely ruptured, 13 were concluded to be partially ruptured and 6 were found to be normal on arthroscopy. An ACL rupture diagnosed on MRI is an important indicator to look for the co - existence of other injuries of that knee joint. Of all the patients accounting for ACL injury ACLs that were classified at MRI as normal were seen to be normal even on arthroscopy. There by giving MRI a negative predictive value of 97.1 percent for ACL injury. Conclusion: MRI increases diagnostic confidence and potentially reduces the need for diagnostic arthroscopy.

Keywords: MRI, Arthroscopy, ACL injury.

Corresponding Author: Dr. Anmol Modi, Fellow in Body imaging, Columbia Asia hospital, Bengaluru, Karnataka.

Received: June 2019

Accepted: June 2019

\section{Introduction}

"Earlier arthroscopy was used mainly for diagnosis, it saved many knees from unnecessary arthrotomy. Today Magnetic Resonance Imaging (MRI) is available to save many knees from unnecessary arthroscopy."

Amongst the vast array of traumatic injuries, knee joint is one of the most commonly affected joint following trauma. Today MRI is the gold standard non invasive investigation for imaging of knee joint.

Trauma of the knee joint is a significant cause of morbidity in young, active individuals especially amongst military recruits, trained soldiers and athletes. An accurate diagnosis regarding the type and extent of injuries is essential for early operative as well as non-operative treatment. This requires an accurate clinical history, a thorough physical examination and complementary diagnostic tools. With the availability of improved surgical options, accurate imaging of the knee becomes all the more imperative.

The knee joint can be imaged using a variety of modalities of which MRI is the most recognized technique posing an excellent imaging modality for all the components of the knee joint namely cartilage, ligaments, tendons, menisci, muscles, bone and bone marrow. Injuries to the intra articular structures can be diagnosed with a high degree of sensitivity and specificity. ${ }^{[1]}$

MRI for imaging of knee joint has very high negative predictive value and may assist in avoiding unnecessary arthroscopy, its accuracy in diagnosis of meniscal and anterior cruciate ligaments is greater than $90 \%$ and also has greater sensitivity for detection of medial meniscal tears and posterior horn is better assessed than arthroscopy. ${ }^{[2]}$

Since its introduction for clinical use in mid 1984 the role of MRI in diagnosing knee lesions has been well established. In the context of trauma post traumatic limited range of motion and mechanical knee symptoms, MRI is considered as the valuable diagnostic tool. ${ }^{[3]}$

Since knee joint is a compound synovial joint and due to lack of any bony support, stability of the joint is highly dependent on its supporting ligamentous structures, therefore injuries of ligaments and menisci are extremely common. ${ }^{[4]}$ MRI has made it possible to look into the injured knee non invasively and able to depict injury to ligaments, tendons, articular cartilage and menisci with accuracy and thereby avoiding invasive procedures and further morbidity. ${ }^{[5]}$

Magnetic resonance imaging, with its exquisite soft-tissue contrast resolution, is the imaging modality of choice for evaluation of acute traumatic musculotendinous abnormalities. MR imaging allows optimal assessment of damage to all components of the musculotendinous unit including the muscle belly, myotendinous junction, and tendon insertion site. In addition, the capability of MR imaging for demonstrating occult muscle trauma makes it a useful tool for assessment of this condition.

Results of various imaging studies been published so far has shown good diagnostic performance in detecting internal derangements of knee. Other advantages of MRI include 


\section{Madi of Madi; MRJ Findings with Arthroscapy in Finee Injuries}

excellent inherent soft tissue contrast, multiplanar imaging, lack of ionising radiation, poses minimal risk if any, produces minimal patient discomfort but the cost of purchasing and maintaining high field strength MR and the often limited availability of such a unit has restricted its widespread use for this purpose.

\section{Subjects and Methods}

Sample size: 75 cases.

\section{Work up of the patient:}

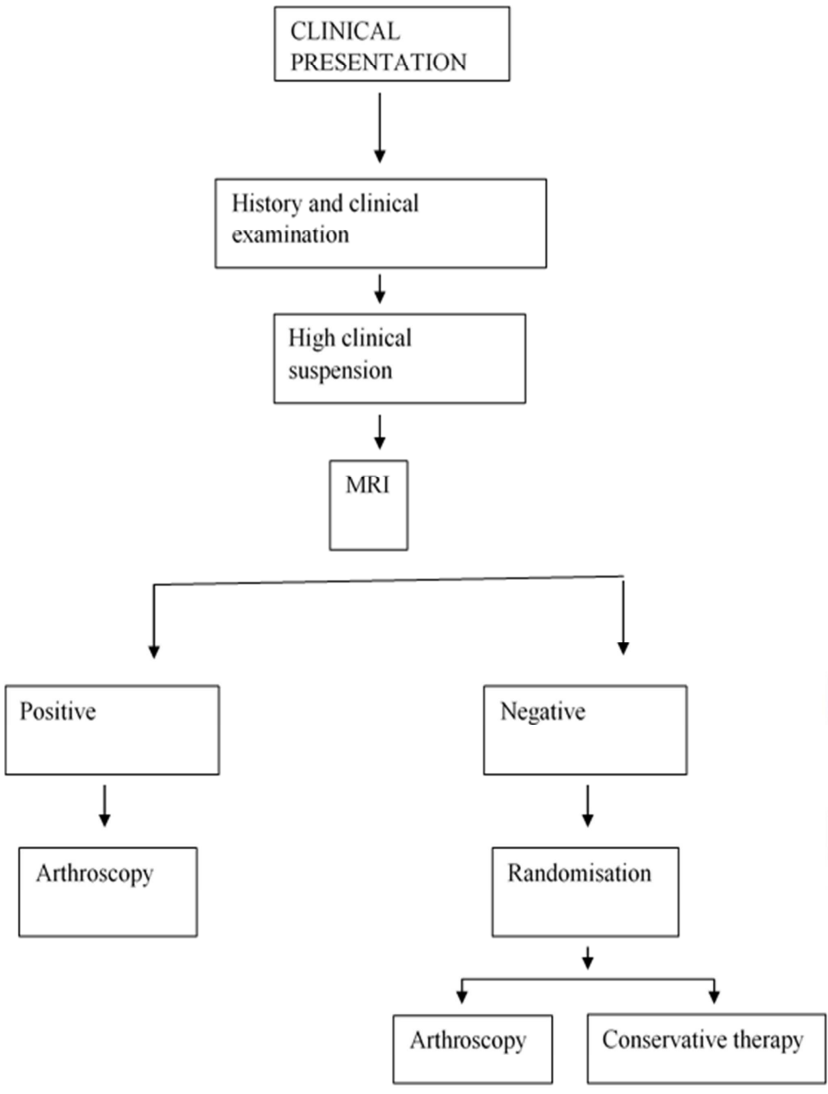

\section{Inclusion Criteria:}

1. Patients with history of pain in the knee with or without swelling where MRI was used as a modality in diagnosing the cause.

2. Patients with clinically suspected tears.

3. Patients with restriction of movement at the knee joint following trivial trauma.

4. Only patients on whom arthroscopy was performed within thirty days of MRI were accepted for the study.

\section{Exclusion Criteria:}

1. Patients with acute traumatic fractures on x-ray

2. Patients diagnosed as having osteochondritis on plain x-ray

3. Patients with cardiac pacemakers and metallic implants were not subjected to MRI.

4. Post-operative cases

5. Motion disorder and claustrophobia, if severe may make the examination difficult.
All patients will be subjected to MR imaging and followed by Arthroscopy.

Results

\begin{tabular}{|l|l|l|l|}
\hline Table 1: Anterior Cruciate Ligament \\
\hline & $\begin{array}{l}\text { Arthroscopy } \\
\text { Positive }\end{array}$ & $\begin{array}{l}\text { Arthroscopy } \\
\text { Negative }\end{array}$ & Total \\
\hline MRI Positive & $34(\mathrm{TP})$ & $6(\mathrm{FP})$ & 40 \\
\hline MRI Negative & $1(\mathrm{FN})$ & $34(\mathrm{TN})$ & 35 \\
\hline Total & 35 & 40 & 75 \\
\hline
\end{tabular}

Table 2: Posterior Cruciate Ligament

\begin{tabular}{|l|l|l|l|}
\hline & $\begin{array}{l}\text { Arthroscopy } \\
\text { positive }\end{array}$ & $\begin{array}{l}\text { Arthroscopy } \\
\text { negative }\end{array}$ & Total \\
\hline MRI positive & $17(\mathrm{TP})$ & $7(\mathrm{FP})$ & 24 \\
\hline MRI negative & $2(\mathrm{FN})$ & $49(\mathrm{TN})$ & 51 \\
\hline total & 19 & 56 & 75 \\
\hline
\end{tabular}

Table 3: Medial Meniscus

\begin{tabular}{|l|l|l|l|}
\hline & $\begin{array}{l}\text { Arthroscopy } \\
\text { positive }\end{array}$ & $\begin{array}{l}\text { Arthroscopy } \\
\text { negative }\end{array}$ & Total \\
\hline MRI positive & $36(\mathrm{TP})$ & \multicolumn{1}{c|}{$11(\mathrm{FP})$} & 47 \\
\hline MRI negative & $8(\mathrm{FN})$ & $20(\mathrm{TN})$ & 28 \\
\hline Total & 44 & 31 & 75 \\
\hline
\end{tabular}

Table 4: Lateral Meniscus

\begin{tabular}{|l|l|l|l|}
\hline & $\begin{array}{l}\text { Arthroscopy } \\
\text { Positive }\end{array}$ & $\begin{array}{l}\text { Arthroscopy } \\
\text { negative }\end{array}$ & Total \\
\hline MRI positive & $30(\mathrm{TP})$ & $0(\mathrm{FP})$ & 30 \\
\hline MRI negative & $0(\mathrm{FN})$ & $45(\mathrm{TN})$ & 45 \\
\hline Total & 30 & 45 & 75 \\
\hline
\end{tabular}

Table 5: Sensitivity And Specificity of MRI For Each

Category

\begin{tabular}{|l|l|l|}
\hline Structures & Sensitivity & Specificity \\
\hline$A C L$ & $97.1 \%$ & $85 \%$ \\
\hline
\end{tabular}

\begin{tabular}{|l|l|l|}
\hline ACL & $97.1 \%$ & $85 \%$ \\
\hline PCL & $89.4 \%$ & $87.5 \%$ \\
\hline Lateral meniscus & $100 \%$ & $100 \%$ \\
\hline Medial meniscus & $81.8 \%$ & $64.5 . \%$ \\
\hline
\end{tabular}

Table 6: Accuracy, PPV And NPV Of MRI For Each Category

\begin{tabular}{|l|l|l|l|}
\hline Structures & Accuracy & PPV & NPV \\
\hline ACL & $79.3 \%$ & $85 \%$ & $97.1 \%$ \\
\hline PCL & $71.6 \%$ & $70.8 \%$ & $96.07 \%$ \\
\hline I.M & $100 \%$ & $100 \%$ & $100 \%$ \\
\hline MM & $74.6 \%$ & $76.5 \%$ & $71.4 \%$ \\
\hline
\end{tabular}

\section{Discussion}

Out of the 40 ACLs diagnosed as completely ruptured at MRI, 27 were confirmed to be completely ruptured, 13 were concluded to be partially ruptured and 6 were found to be normal on arthroscopy. An ACL rupture diagnosed on MRI is an important indicator to look for the co - existence of other injuries of that knee joint. Of all the patients accounting for ACL injury ACLs that were classified at MRI as normal were seen to be normal even on arthroscopy. There by giving MRI a negative predictive value of 97.1 percent for ACL injury.

6 ACLs that were classified at MRI as thickened, 


\section{Madi d Madi; MRJ Findings with Orthroscapy in Tnee Injuries}

edematous or seen to show intrasubstance tears were all seen to be normal on arthroscopy. However there were no associated meniscal tears reported.

Overall sensitivity of ACL tears on MRI was calculated to be 97.1 percent with a specificity of 85 percent.

Out of the 40 patients showing ACL tear on MRI, 12 patients also showed associated Grade II posterior horn of Medial meniscus tear in 3 patients and Grade III tear of posterior horn of Medial meniscus tear in 9 patients.

27 patients with ACL tear on MRI showed associated contusions involving the lateral condyle of the tibia, in addition 6 were associated with bone marrow edema involving the medial femoral condyle. One patient was reported to have an associated partial tear of the posterior cruciate ligament which was found to be normal on arthroscopy.

Our study correlated with the study done by Bui-Mans field et al6 ho showed that complete ACL tears were associated with tear of posterior horn of the lateral meniscus. They also found a sensitivity of $94 \%$ and specificity of $93 \%$ for a composite diagnosis at MRI in a group of 50 patients selected on the basis of criteria related to surgical indications for monitoring appropriateness. Christine W. Heron et $\mathrm{al}^{[7]}$ in MRI found sensitivity of $92 \%$ in the diagnosis of complete tear of Anterior Cruciate Ligament and a specificity of $96 \%$.

In another study conducted by Murray A. Reicher et al, ${ }^{[8]}$ showed that out of 20 patients with ACL tear on MRI 12 were found to be completely disrupted and 4 cases were falsely positive on MR imaging. In these cases it was found that the ACL was obscured by the presence of a joint effusion with similar signal intensity (haemarthrosis).

Naranje $\mathrm{S}$ et $\mathrm{al},{ }^{[9]}$ conclude from our study that in chronic ACL-deficient patients, the prevalence of posterior horn medial meniscus tears seems to be high. Anterior horn tears and radial and horizontal patterns of meniscus tears seem to be rare in chronic ACL deficiency. MRI correlates well with arthroscopy and has high negative predictive values. On sagittal images, the normal PCL was depicted as low intensity, arc like band outlined by high intensity intra articular fat. The PCL is much stronger a ligament than the $\mathrm{ACL}$ is seen prove to rupture infrequently as compared to the ACL and the menisci.

In our study we reported 24 cases of complete rupture of the PCL, 19 cases were proved on arthroscopy.

However, 51 cases reported negative (normal) on MRI, 49 cases were found to be negative at arthroscopy. Thus the negative predictive value of MRI for PCL tears was $96.7 \%$. In our study the sensitivity of MRI for PCL tears was found to be $89.4 \%$ and the specificity was $87.5 \%$.

George W. Gallimore et allo found that MRI proved very useful for evaluating cruciate ligament injury especially the PCL.

Studies performed by Christine W. Heron et al, ${ }^{[11]}$ have compared the findings on MRI of the knee obtained with a three - dimensional(3D) gradient echo (GRE) sequence with findings at arthroscopy, the menisci, cruciate ligaments and hyaline cartilage were assessed in 100 patients. They found sensitivity and specificity of MRI in diagnosing PCL were $100 \%$.
Studies performed by Christine W. Heron et al, ${ }^{[1]}$ showed that partially ruptured PCLs were found to be normal at arthroscopy. The reason attributed by Reicher et al was that the presence of fluid around PCL with a signal intensity same as that of the PCL made it difficult for its visualization.

On analysis of our cases, we also found the same reason as mentioned by Reicher et al in their study.

In the study done by Murray A. Reicher et al, ${ }^{[8]}$ it was found that 3 cases with clinical suspicion of PCL rupture were seen to show disruption of the PCL fibres on MR images, out of which only 2 cases showed PCL rupture on surgery. In the third case, the PCL had a slightly diffuse increase in signal intensity. At arthroscopy the patient was found to have a scarred and lax but otherwise normal intact PCL.

Saurav Singla, Nitin Kansal et al, ${ }^{[12]}$ in their study shown the sensitivity and specificity of MRI for PCL tear to be $80 \%$ and $94.2 \%$ respectively.

On MRI 44 cases were reported as Grade II \& III tears of the posterior horn of the medial meniscus of which 33 cases showed positive correlation with arthroscopy. 03 cases that were reported to show Grade I tear were negative on arthroscopy. 8 cases that were reported as normal in MRI showed tear on arthroscopy, thereby showing a negative predictive value of $71.4 \%$.

The sensitivity of MRI in diagnosing medial meniscus was found to be $81.8 \%$ and the specificity was found to be $64.5 \%$.

In a study Christine W. Heron et al, ${ }^{[7]}$ have compared the findings on MRI of the knee obtained with a 3D-GRE sequence with findings at arthroscopy, the menisci, cruciate ligaments and hyaline cartilage were assessed in 100 patients. The sensitivity of MRI in diagnosis of meniscal tears seen at arthroscopy was $97 \%$ and the specificity $94 \%$.

Mahmoud Karimi-Mobarake, Hamid Barani-Baravati et al, ${ }^{[13]}$ showed accuracy of MRI for detecting MM tear to be $72.2 \%$.

Elvenes J, Jerome CP, Reikeras O,Johansen O et al, ${ }^{[14]}$ have compared with arthroscopy, the sensitivity, specificity, positive predictive value and negative predictive value for MRI for the nmedial meniscus were $100 \%, 77 \%, 71 \%$ and $100 \%$, respectively

Out of 75 patients, 30 cases were reported to show Grade III tear and 30 cases showed a positive correlation on arthroscopy.

The sensitivity for lateral meniscal tears in our study was found to be $100 \%$ and specificity was $100 \%$.

John V. Crues et al, ${ }^{[14]}$ studied meniscal tears of the knee and found that MRI findings and surgical findings agreed in $91.3 \%$ of menisci. MRI was seen to separate surgically significant from insignificant meniscal lesions and was useful in the non-invasive preoperative screening of suspected meniscal tears.

Stoller et al, ${ }^{[15]}$ described 2 menisci of which MRI showed a Grade III signal. The menisci when removed was seen to be normal on gross inspection but were found histologically to have frank intrasubstance tears.

Literature contains reports of clinically significant intrasubstance tears missed at arthroscopy, when a meniscus was not probed and like wise missed at arthrotomy when 


\section{Madi of Madi; MRI Findings with Orthroscapy in Tinee Injuries}

the meniscus was not completely removed and pathologically evaluated.

As already mentioned above, complete ACL tears were associated with tear of posterior horn of medial meniscus (21 out of 33 patients) which were imaged on MRI and proved on arthroscopy.

9 of our cases had associated lateral complex injuries associated with intrasubstance tear of ACL, bone marrow edema involving the lateral tibial and femoral condyles. The case which showed complete tear of PCL had fluid around the MCL (Grade II injury), menisco femoral separation of the posterior horn of medial meniscus with associated contusion of the medial tibial condyle.

Patrice WJ et al, ${ }^{[16]}$ in their study of effectiveness of MRI in the selection of patients for arthroscopy of the knee made a positive composite diagnosis of various injuries at MRI which were proved on arthroscopy.

\section{Conclusion}

Magnetic Resonance Imaging of the knee has the potential for a rapid, definitive diagnosis with a non invasive examination in comparison to gold standard arthroscopy.

\section{References}

1. Aydingoz U, Firat AK, Atay OA, Doral MN. MR Imaging of meniscal bucket handle tear ; A Review of signs and their relation to arthroscopic classification.Eur Radiol.2003;13(3);618625

2. Sarah Skinner MRI of Knee Aus Fam Physician 2012 Nov;(11):867-9

3. Edwin HG Oei, Jeroren J Nikken, Antonia CM Verstijen, Abida Z Ginai, MG Myriam Hunik MAGNETIC RENOSANCE IMAGING FOR TRAUMATIC KNEE INJURY . A REVIEW ultrasound CT MRI 2007;28:141-157
4. David K B Li, Mark E Adams, Pat McConkey, MRI of ligaments and menisci of the knee. Radiol, Clin North Am 1986; 24(2); 209-227

5. SinghJP,GargL,ShrimaliR,Sethia V Imaging of knee with arthroscopic correlation with twisting injuries Indian journal of radiology imaging 2004; 14: 33-40

6. Christine $\mathrm{W}$. Heron et al three dimensional gradient echo MR imaging of the knee: comparison with arthroscopy. Radiology, v.183 no. 3 pp.839 - 844, [1992]| 0033-8419

7. 7. Amreen Abdul Bari et al Evaluation of MRI Versus Arthroscopy in Anterior Cruciate Ligament and Meniscal Injuries J Clin Diagn Res. 2014 Dec; 8(12): RC14-RC18. Published online 2014 Dec 5

8. Patrice W.J. Vincken et al. Effectiveness of MR imaging in selection of patients for arthroscopy of the knee. Radiology 2002;223:739-746.

9. Naranje S,Mittal R,Sharma R.Arthroscopic and magnetic resonance imaging evaluation of meniscus lesions in the chronic anterior cruciate ligament deficient knee.Arthroscopy. 008Sep;24(9):1045-51doi: 10.1016/j.arthro.2008.03.008.Epub 2008 May 15

10. MRI Evaluation of Painful Knee : A Study at katuri Tertiary Referral Center . Journal of evidence based Medicine and Health care; Volume 2, Issue 7 , February 16, 2015; Page 888- 897.

11. Amreen Abdul Bari et al Evaluation of MRI Versus Arthroscopy in Anterior Cruciate Ligament and Meniscal Injuries J Clin Diagn Res. 2014 Dec; 8(12): RC14-RC18. Published online 2014 Dec 5. Doi.

12. Saurav Singla, Nitin Kansal et al sensitivity and specificity of MRI versus Arthroscopy in internal derangement of knee, International Journal of Scientific and Research Publications, Volume 3, Issue 4, April 20131 ISSN 2250-3153

13. Mahmoud Karimi-Mobarake, Hamid Barani-Baravati. The Accuracy of Magnetic Imaging Compared with Arthroscopic. Finding in Intraarticular Traumatic Knee Injury.Journal Applied Sciences 2005; 5(4): 686-688.

14. Omar Faiz, David Moffat. The knee joint and Popliteal Fossa. In: Omar Faiz, David Moffat, editor. Anatomy at a glance. (5th ed.) University of Cardiff: Blackwell Science Ltd, 2002:109-112.

15. Sykes JT, Mulligan SA. Australas Radiol. MRI of internal derangement of the knee with arthroscopic correlation.1990 Aug;34(3):207-10

16. Rudresh Halawar et al Occurrence of isolated and combined anterior cruciate ligament injuries in traumatic knee-by MRI Medica Innovatic7a, December 2014, Volume 3 - Issue 2

Copyright: () the author(s), publisher. Asian Journal of Medical Radiological Research is an Official Publication of "Society for Health Care \& Research Development". It is an open-access article distributed under the terms of the Creative Commons Attribution Non-Commercial License, which permits unrestricted non-commercial use, distribution, and reproduction in any medium, provided the original work is properly cited.

How to cite this article: Modi PG, Modi A. Comparison of MRI Findings with Arthroscopy in Knee Injuries. Asian J. Med. Radiol. Res. 2019;7(1):83-86.

DOI: dx.doi.org/10.21276/ajmrr.2019.7.1.18

Source of Support: Nil, Conflict of Interest: None declared. 